\title{
Complex abdominal wall hernia repair with biologic mesh in elderly: a propensity matched analysis
}

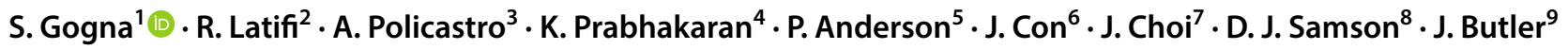

Received: 10 July 2019 / Accepted: 4 October 2019 / Published online: 24 January 2020

c) Springer-Verlag France SAS, part of Springer Nature 2020

\begin{abstract}
Background Complex abdominal wall reconstruction (CAWR) has become a common surgical procedure both in non-elderly and elderly patients.

Objective The aim of this study is to analyze the outcomes of the elderly compared to nonelderly undergoing CAWR using propensity score matching.

Methods All patients who underwent CAWR using porcine-derived, non-crosslinked acellular dermal matrix (ADM) (Strattice $^{\mathrm{TM}}$ ) between January 2014 and July 2017 were studied retrospectively. Propensity matched analysis was performed for risk adjustment in multivariable analysis and for one-to-one matching. The outcomes were analyzed for differences in postoperative complications, reoperations, mortality, hospital length of stay and adverse discharge disposition.

Results One hundred-thirty-six patients were identified during the study period. Non-elderly (aged 18-64 years) constituted $70 \%(n=95)$ and elderly (aged $\geq 65$ years) comprised $30 \%$ of the overall patient population $(n=41)$. Seventy-three $(56.7 \%)$ were females. After adjustment through the propensity score, which included 35 pairs, the surgical site infection $(p=1.000)$, wound necrosis $(p=1.000)$, the need for mechanical ventilation $(p=0.259)$, mortality $(p=0.083)$, reoperation rate $(p=0.141)$, hospital length of stay $(p=0.206)$, and discharge disposition $(p=0.795)$ were similar.

Conclusion Elderly patients undergoing CAWR with biological mesh have comparable outcomes with non-elderly patients when using propensity matching score.
\end{abstract}

Keywords Hernia Complex abdominal wall reconstruction · Biologic mesh · Elderly · Posterior component release · Outcomes $\cdot$ Complications $\cdot$ Propensity matching

\section{Introduction}

In the USA by 2050 , the population aged 65 and over is projected to be 83.7 million, double the estimated number of 43.1 million in 2012 [1]. This demographic shift in the population will have implications in terms of a higher proportion of elderly undergoing major surgery.

A ventral hernia is one of the most common consequences after laparotomy and often require complex abdominal wall reconstruction (CAWR) [2-4]. Yet, studies on outcomes after complex abdominal wall reconstruction (CAWR) in the elderly populations are very limited. There is evidence that postoperative morbidity and mortality is higher in elderly as compared to non-elderly and

R. Latifi

Rifat.Latifi@wmchealth.org

Extended author information available on the last page of the article increasing age itself remains an independent risk factor for postoperative morbidity and mortality [5]. The world health organization (WHO) consider the chronological age of 65 years as an 'elderly' or older person [6]. Similarly, in the United States also age $\geq 65$ is considered elderly [7]. The biologic mesh has been suggested in the contaminated field or high-risk patients [8-10] undergoing CAWR. We use non-cross linked acellular porcine dermal matrix (Strattice ${ }^{\mathrm{TM}}$ ) in all patients at high-risk for infections and those with contaminated field undergoing CAWR. Our initial results of CAWR with Strattice ${ }^{\mathrm{TM}}$ were encouraging hence this particular mesh type was utilized [11].

This study aimed to analyze the outcomes of the elderly compared to non-elderly undergoing CAWR using biological mesh as reinforcement by utilizing propensity score matching. 


\section{Methods}

We performed a retrospective cohort review of all patients aged $\geq 18$ years who underwent CAWR using a porcinederived acellular dermal matrix (Strattice ${ }^{\mathrm{TM}}$ ) for complex abdominal wall hernia at Westchester Medical Center, Valhalla, NY from 2014 to 2016 . The patient population was divided into two groups; non-elderly aged 18-64 years and elderly aged $\geq 65$ years. Before designing the study, classification for primary and incisional abdominal wall hernias proposed by Muysoms et al., and criteria for CAWD outlined by Slater et al., was used to establish the inclusion criteria [12]. The study was approved by the Institutional Review Board.

\section{Inclusion criteria}

Patients aged $\geq 18$ years who underwent CAWR with biological mesh falling into the criteria proposed by the consensus group [8].

\section{Exclusion criteria}

Patients with age $<18$ years, use of synthetic mesh, simple incisional hernia closed primarily.

\section{Variables and outcomes}

The data were collected for patient demographics, etiology of hernia, past surgical history, and comorbid conditions. Intraoperative variables included the surgical approach (type of incision), lysis of adhesions, type of component separation (anterior, posterior or combined), mesh type, size, and placement technique, and associated procedures (intestinal resection, stoma/fistula takedown, panniculectomy, and redundant skin excision), and finally number of drains. Propensity scores were calculated using a logistic regression model using the following variables: age, sex, body mass index, modified frailty index, hypertension, diabetes mellitus, chronic obstructive pulmonary disease (COPD), chronic kidney disease, ischemic heart disease, cirrhosis, malignancy, dementia, obesity, arthritis, psychiatric disorder, patient functionality, peripheral vascular disease, type of prior surgery, mesh size and number of drains.

The outcome measures were mortality, hospital length of stay, intensive care length of stay, need for mechanical ventilation, surgical site infection, seroma, need for reoperation and adverse discharge disposition.
Surgical site infections were defined using the US Centers for Disease Control and Prevention criteria for superficial and deep incisional SSI. These criteria require the patient to have at least one of the following: (1) purulent drainage from the superficial or deep (fascia or muscle) incision but not from within the organ or space component of the surgical site; (2) pain or tenderness, localized swelling, redness, heat, or fever, or several of these symptoms, and the incision is opened deliberately or spontaneously dehisces; or (3) abscess within the wound (clinically or radiologically detected) $[13,14]$. Post-operative seroma, if present, was defined according to the classification proposed by Morales et al. [15] Adverse discharge disposition was defined as the discharge to an acute or sub-acute rehabilitation center. The modified frailty index $(\mathrm{mFi})$ score was calculated based on Velanovich et al. [16], while the uniformity in reporting the outcome results after abdominal wall repair was ensured using the recommendations from Muysom et al. at EuraHS Working Group (European Registry of Abdominal Wall Hernias) [17].

\section{Surgical technique}

The choice of mesh to strengthen the reconstruction of the abdominal wall in all the patients was an acellular porcine dermal matrix (Strattice ${ }^{\mathrm{TM}}$ ). Mesh placement techniques employed in our patient population were: sublay (retro-rectus), underlay (intraperitoneal), onlay or bridge However, since 2017 our group has changed the mesh placement technique from intraperitoneally (underlay) and anterior component separation $[18,19]$ to posterior component separation (PCS) with or without transversus abdominis release (TAR) and sublay (retro-rectus) mesh placement [20-22]. During PCS we ensure the sparing of all neurovascular bundles.

The linea alba is closed over the mesh whenever possible. During the closing of the abdominal wall, we measure airway peak pressure. The increase of up to $5 \mathrm{~cm} \mathrm{H} 20$ change from the open state to closed linea alba is deemed acceptable. We place two or three 19-french Blake drains below the fascia-adipocuatneous flaps.

\section{Statistical analysis}

Summary statistics are presented as frequencies and percentages for the categorical variable. The continuous data are presented as mean and standard deviation. The data were compared using the independent student $t$ test for continuous variables and the Chi-squared test for categorical variables before matching; after matching, $p<0.05$ was considered significant. We performed one-to-one pair propensity score matching using nearest neighbor matching with no replacement (a single participant could not be selected multiple 
times). Propensity scores were predicted probabilities of the logistic regression equation for individual covariate patterns. Tolerance for matching was set at 0.2 . The analysis was conducted using SPSS 25 software (IBM, Inc., Armonk NY, USA). The study report complies with the STROBE criteria [23].

\section{Results}

During the study period, we included 136 patients who underwent CAWR with biological mesh from January 2014 to July 2017. Non-elderly (aged 18-64 years) constituted $70 \%(n=95)$ and elderly (aged $\geq 65$ years) were $30 \%(n=41)$. There were 73 females $(56.7 \%)$ and 63 males $(46.3 \%)$.

After one to one propensity matching, we created 35 pairs of elderly and non-elderly (age 18-64 years). Thus, six elderly patients lacked matches within the tolerance threshold and were not included in the analyses in the PSM group.

\section{Baseline characteristics}

As shown in Table 1, the significant variables in elderly were: age $(75.7 \pm 6.8$ years in elderly vs. $49.4 \pm 11.3$ years in non-elderly, $p<0.001)$, frailty $(24.4 \%$ vs. $9.5 \%, p=0.02)$, presentation to the hospital with small bowel obstruction ( $22 \%$ vs. $9.5 \%, p=0.049)$, and comorbidities such as hypertension $(82.9 \%$ vs. $51.6 \%, p=0.001)$, and malignancy $(39.0 \%$ vs. $13.7 \%, p=0.00)$. The nonelderly group had a higher percentage of hernia as chief complaint $(83.2 \%$ vs. $61.0 \%, p=0.005$ ). Elderly were more dependent on caregivers or family members for the activities of daily living (ADL) $(47.5 \%$ vs. $23.4 \%, p=0.006)$.

After PSM, two pairs of 35 patients were obtained. An analysis of the baseline characteristics was performed to evaluate the accuracy of the method, as shown in Table 1. There were no significant differences between the two matched groups regarding patient baseline characteristics. The groups were similar in terms of age, frailty, presentation, and comorbidities after controlling for confounders.

\section{Operative characteristics}

Table 2 shows that before PSM, the type of incision, intestinal resection rate $(20.0 \%$ vs. $20.2 \%, p=0.977)$, ECF take down $(4.9 \%$ vs. $7.4 \%, p=0.7228)$ and stoma take down (7.3\% vs. $10.6 \%, p=0.753)$ were statistically similar in both age groups. Similarly, retro-rectus mesh placement ( $64.1 \%$ in elderly vs. $63.7 \%$ in non-elderly), and bridge mesh placement ( $17.9 \%$ in elderly vs. $19.8 \%$ in non-elderly) were comparable in both age groups. However, the underlay technique was used more commonly in the elderly (17.9\% vs. $5.5 \%, p=0.026)$ and onlay technique was more common in the non-elderly $(11.0 \%$ vs. $0 \%, p=0.026)$. The Center for Disease Control (CDC) wound class II, III, IV were similar for both groups $(43.9 \%$ in elderly vs. $48.4 \%$ in non-elderly, $p=0.628)$. The panniculectomy rates $(2.4 \%$ in elderly vs. $5.3 \%$ in non-elderly, $p=0.667$ ), mean mesh size $\left(544.81 \pm 580.9 \mathrm{~cm}^{2}\right.$ in elderly vs. $449.8 \pm 257.5 \mathrm{~cm}^{2} \%$ in non-elderly, $p=0.241$ ) and number of drains placed $(2.21 \pm 1.1$ in elderly vs. $1.99 \pm 1.3$ in non-elderly, $p=0.355)$ were also similar.

After PSM, as shown in Table 2, the difference between mesh placement techniques was found to be non-significant for all placement locations $(p=0.255)$. All other major operative characteristics including type of operative approach, $\mathrm{CDC}$ wound class II/III/IV ( $p=0.632)$, panniculectomy rates $(p=1.000)$, excision of redundant skin $(p=0.062)$, primary wound closure rates $(p=1.000)$, mesh size $(p=0.377)$ and the number of drains placed $(p=0.235)$ remained statistically similar.

\section{Post-operative outcomes}

The postoperative outcomes for the two groups before and after PSM are depicted in Table 3. Overall intraoperative complication rate $(4.9 \%$ in elderly vs. $1.1 \%$ in nonelderly, $p=0.216)$, surgical site infection rate $(7.3 \%$ in elderly vs. $6.4 \%$ in non-elderly, $p=1.000$ ), wound necrosis $(2.5 \%$ vs. $3.2 \%, p=1.000)$ and need for a wound VAC ( $22.0 \%$ in elderly vs. $21.1 \%$ in non-elderly, $p=0.907$ ) were comparable.

The postoperative need for mechanical ventilation was significantly higher in the elderly as compared to the nonelderly (22.0\% in elderly vs. $5.0 \%$ in non-elderly, $p=0.006)$. A higher proportion of the elderly was discharged to skilled nursing facilities $(16.2 \%$ in elderly vs. $4.3 \%$ in non-elderly, $p=0.024$ ) and subacute rehabilitation centers (in elderly $18.9 \%$ vs. $14.1 \%$ in nonelderly, $p=0.024$ ). The statistically higher number of non-elderly patients were discharged home as compared to the elderly ( $77.8 \%$ vs. $56.8 \%)$. The inhospital mortality ( $7.3 \%$ in elderly vs. $1.1 \%$ in non-elderly, $p=0.083)$, the reoperation rate $(12.2 \%$ in elderly vs. $23.2 \%$ in non-elderly, $p=0.141$ ) and the hospital length of stay $(17.49 \pm 26.84$ days in elderly vs. $12.79 \pm 14.44$ days in nonelderly, $p=0.206$ ) were statistically similar in both groups.

After PSM, as shown in Table 3, the need for postoperative mechanical ventilation was statistically similar between the two groups (17.1\% in elderly vs. $5.7 \%$ in non-elderly, $p=0.259$ ).

The discharge disposition was also similar. A statistically similar percentage of elderly were discharged to home ( $67.7 \%$ vs. $76.5 \%$ non-elderly, $p=0.795$ ), to skilled nursing facilities ( $12.9 \%$ vs. $5.9 \%$ non-elderly, $p=0.795)$ and to 
Table 1 Baseline characteristics of elderly vs non-elderly patients undergoing complex abdominal wall reconstruction with acellular porcine dermal matrix

\begin{tabular}{|c|c|c|c|c|c|c|}
\hline & \multicolumn{3}{|l|}{ Overall series } & \multicolumn{3}{|c|}{ Propensity-matched series } \\
\hline & $\begin{array}{l}\text { Non-elderly, } \\
N=95(\%)\end{array}$ & Elderly, $N=41(\%)$ & $p$ value & $\begin{array}{l}\text { Non-elderly, } \\
N=35(\%)\end{array}$ & Elderly $N=35(\%)$ & $p$ value \\
\hline Age (years) & $49.4 \pm 11.3$ & $75.7 \pm 6.8$ & $<0.001 *$ & $53.7 \pm 9.1$ & $75.5 \pm 6.7$ & $<0.001 *$ \\
\hline Gender & & & $0.025^{*}$ & & & 0.053 \\
\hline Male & $50(52.6 \%)$ & $13(31.7 \%)$ & & $19(54.3 \%)$ & $11(31.4 \%)$ & \\
\hline Female & $45(47.4 \%)$ & $28(68.3 \%)$ & & $16(45.7 \%)$ & $24(68.6 \%)$ & \\
\hline Body mass index (BMI $\mathrm{Kg} / \mathrm{m}^{2}$ ) & $32.2 \pm 10.3$ & $31.0 \pm 6.9$ & 0.52 & $32.0 \pm 9.1$ & $31.1 \pm 6.4$ & 0.607 \\
\hline Frailty $(\mathrm{mFI} 3+)$ & $9(9.5 \%)$ & $10(24.4 \%)$ & $0.02 *$ & $6(17.1 \%)$ & $6(17.1 \%)$ & 1.00 \\
\hline \multicolumn{7}{|l|}{ Presentation } \\
\hline Hernia & $79(83.2 \%)$ & $25(61.0 \%)$ & $0.005^{*}$ & $25(71.4 \%)$ & $22(62.9 \%)$ & 0.445 \\
\hline Enterocutaneous fistula & $9(9.5 \%)$ & $2(4.9 \%)$ & 0.504 & $5(14.3 \%)$ & $1(2.9 \%)$ & 0.198 \\
\hline Small bowel obstruction & $9(9.5 \%)$ & $9(22.0 \%)$ & $0.049^{*}$ & $617.1 \%)$ & $7(20.0 \%)$ & 0.749 \\
\hline \multicolumn{7}{|l|}{ Prior predisposing condition } \\
\hline Trauma & $14(14.7 \%)$ & $4(9.8 \%)$ & 0.432 & $2(5.7 \%)$ & $4(11.4 \%)$ & 0.673 \\
\hline Elective intraabdominal surgery & $45(47.4 \%)$ & $17(41.5 \%)$ & 0.526 & $14(40.0 \%)$ & $16(45.7 \%)$ & 0.732 \\
\hline Diverticulitis & $10(10.5 \%)$ & $49.8 \%)$ & 1.000 & $4(11.4 \%)$ & $4(11.4 \%)$ & 1.000 \\
\hline Other colonic surgery & $7(7.4 \%)$ & $5(12.2 \%)$ & 0.511 & $1(2.9 \%)$ & $4(11.4 \%)$ & 0.356 \\
\hline Small bowel obstruction & $6(6.3 \%)$ & $2(4.9 \%)$ & 1.000 & $4(11.4 \%)$ & $2(5.7 \%)$ & 0.673 \\
\hline Urologic surgery & $4(4.2 \%)$ & $3(7.3 \%)$ & 0.430 & $2(5.7 \%)$ & $3(8.6 \%)$ & 1.000 \\
\hline Obstetric/gynecologic & $13(13.7 \%)$ & $6(14.6 \%)$ & 0.883 & $4(11.4 \%)$ & $6(17.1 \%)$ & 0.734 \\
\hline Cancer & $8(8.4 \%)$ & $6(14.6 \%)$ & 0.356 & $822.9 \%)$ & $5(14.3 \%)$ & 0.356 \\
\hline \multicolumn{7}{|l|}{ Solid organ transplant } \\
\hline Heart transplant & $3(3.2 \%)$ & 0 & 0.554 & $1(2.9 \%)$ & 0 & 1.000 \\
\hline Liver transplant & $10(10.5 \%)$ & $2(4.9 \%)$ & 0.510 & $5(14.3 \%)$ & $2(5.7 \%)$ & 0.428 \\
\hline Kidney transplant & $8(8.4 \%)$ & $1(2.4 \%)$ & 0.277 & $2(5.7 \%)$ & 0 & 0.493 \\
\hline Open abdomen management & $15(15.8 \%)$ & $8(19.5 \%)$ & 0.595 & $4(11.4 \%)$ & $7(20.0 \%)$ & 0.324 \\
\hline \multicolumn{7}{|l|}{ Setting } \\
\hline Elective & $68(71.6 \%)$ & $24(58.5 \%)$ & 0.136 & $24(68.6 \%)$ & $22(62.9 \%)$ & 0.615 \\
\hline Urgent/emergent & $27(28.4 \%)$ & $17(41.5 \%)$ & & $11(31.4 \%)$ & $13(37.1 \%)$ & \\
\hline \multicolumn{7}{|l|}{ Comorbidity } \\
\hline Congestive heart failure & $3(3.2 \%)$ & $2(4.9 \%)$ & 0.637 & 0 & $1(2.9 \%)$ & 1.000 \\
\hline Dialysis & $3(3.2 \%)$ & $3(7.3 \%)$ & 0.365 & $1(2.9 \%)$ & $2(5.7 \%)$ & 1.000 \\
\hline Acute renal failure & $2(2.1 \%)$ & 0 & 1.000 & $2(5.7 \%)$ & 0 & 0.493 \\
\hline Chronic steroid use & $13(13.7 \%)$ & $3(7.3 \%)$ & 0.390 & $5(14.3 \%)$ & $3(8.6 \%)$ & 0.710 \\
\hline Cardiac disease & $\begin{array}{l}12 \\
(12.6 \%)\end{array}$ & $\begin{array}{l}10 \\
(24.4 \%)\end{array}$ & 0.087 & $5(14.3 \%)$ & $8(22.9 \%)$ & 0.356 \\
\hline Hypertension & $49(51.6 \%)$ & $34(82.9 \%)$ & $0.001 *$ & $23(65.7 \%)$ & $28(80.0 \%)$ & 0.179 \\
\hline COPD & $11(11.6 \%)$ & $6(14.6 \%)$ & 0.621 & $3(8.6 \%)$ & $5(14.3 \%)$ & 0.710 \\
\hline Cirrhosis & $8(8.5 \%)$ & $5(12.2 \%)$ & 0.533 & $2(5.7 \%)$ & $5(14.3 \%)$ & 0.428 \\
\hline Smoking & $16(17.0 \%)$ & $6(14.6 \%)$ & 0.729 & $4(11.4 \%)$ & $6(17.1 \%)$ & 0.734 \\
\hline Alcohol abuse & $16(17.0 \%)$ & $2(4.9 \%)$ & 0.056 & $3(8.6 \%)$ & $2(5.7 \%)$ & 1.000 \\
\hline Drug abuse & $5(5.3 \%)$ & $1(2.4 \%)$ & 0.667 & 0 & $1(2.9 \%)$ & 1.000 \\
\hline Malignancy & $13(13.7 \%)$ & $16(39.0 \%)$ & $0.001 *$ & $13(37.1 \%)$ & $12(34.3 \%)$ & 0.803 \\
\hline Diabetes & $26(27.4 \%)$ & $17(41.5 \%)$ & 0.104 & $15(42.9 \%)$ & $14(40.0 \%)$ & 0.808 \\
\hline Obesity & $45(48.4 \%)$ & $18(43.9 \%)$ & 0.631 & $16(45.7 \%)$ & $16(45.7 \%)$ & 1.000 \\
\hline Arthritis & $6(6.3 \%)$ & $3(7.3 \%)$ & 1.000 & $2(5.7 \%)$ & $2(5.7 \%)$ & 1.000 \\
\hline Psychiatric disorder & $17(17.9 \%)$ & $3(7.3 \%)$ & 0.109 & $8(22.9 \%)$ & $3(8.6 \%)$ & 0.101 \\
\hline Patient functionally dependent & $22(23.4 \%)$ & $19(47.5 \%)$ & $0.006^{*}$ & $10(28.6 \%)$ & $14(40.0 \%)$ & 0.313 \\
\hline Altered sensorium & $6(6.7 \%)$ & $5(12.5 \%)$ & 0.314 & $2(5.7 \%)$ & $4(11.8 \%)$ & 0.428 \\
\hline
\end{tabular}


Table 1 (continued)

\begin{tabular}{|c|c|c|c|c|c|c|}
\hline & \multicolumn{3}{|c|}{ Overall series } & \multicolumn{3}{|c|}{ Propensity-matched series } \\
\hline & $\begin{array}{l}\text { Non-elderly, } \\
N=95(\%)\end{array}$ & Elderly, $N=41(\%)$ & $p$ value & $\begin{array}{l}\text { Non-elderly, } \\
N=35(\%)\end{array}$ & Elderly $N=35(\%)$ & $p$ value \\
\hline Peripheral vascular disease & $5(5.3 \%)$ & $5(12.2 \%)$ & 0.168 & $4(11.4 \%)$ & $4(11.4 \%)$ & 1.000 \\
\hline
\end{tabular}

*Significant at $p<0.05$

Table 2 Comparison of operative characteristics of elderly vs non-elderly patients undergoing complex abdominal wall reconstruction with acellular porcine dermal matrix

\begin{tabular}{|c|c|c|c|c|c|c|}
\hline & \multicolumn{3}{|l|}{ Overall series } & \multicolumn{3}{|l|}{ Propensity-matched series } \\
\hline & Non-elderly, $N=95(\%)$ & Elderly, $N=41(\%)$ & $p$ value & Non-elderly, $N=35(\%)$ & Elderly $N=35(\%)$ & $p$ value \\
\hline \multicolumn{7}{|l|}{ Type of incision } \\
\hline Midline & $73(77.7 \%)$ & $31(75.6 \%)$ & 0.794 & $25(71.4 \%)$ & $27(77.1 \%)$ & 0.584 \\
\hline Flank & $2(2.1 \%)$ & $1(2.4 \%)$ & 1.000 & $0(0.0 \%)$ & $1(2.9 \%)$ & 1.000 \\
\hline Para median & $5(5.3 \%)$ & $4(9.8 \%)$ & 0.453 & $2(5.7 \%)$ & $4(11.4 \%)$ & 0.673 \\
\hline Left lower quadrant & 0 & $2(4.9 \%)$ & 0.090 & 0 & $1(2.9 \%)$ & 1.000 \\
\hline Left upper quadrant & $3(3.2 \%)$ & $1(2.4 \%)$ & 1.000 & $3(8.6 \%)$ & 0 & 0.239 \\
\hline Right upper quadrant & $5(5.3 \%)$ & 0 & 0.322 & $2(5.7 \%)$ & 0 & 0.492 \\
\hline Right lower quadrant & $2(2.1 \%)$ & $1(2.4 \%)$ & 1.000 & 0 & $1(2.9 \%)$ & 1.000 \\
\hline Bilateral subcostal & $7(7.4 \%)$ & $1(2.4 \%)$ & 0.434 & $3(8.6 \%)$ & $1(2.9 \%)$ & 0.614 \\
\hline Lysis of adhesions & $73(76.8 \%)$ & $27(65.9 \%)$ & 0.182 & $28(80.0 \%)$ & $22(62.9 \%)$ & 0.112 \\
\hline Intestinal resection & $19(20.2 \%)$ & $8(20.0 \%)$ & 0.977 & $9(25.7 \%)$ & $6(17.6 \%)$ & 0.417 \\
\hline Fistula take down & $7(7.4 \%)$ & $2(4.9 \%)$ & 0.722 & $4(11.8 \%)$ & $1(2.9 \%)$ & 0.198 \\
\hline Stoma take down & $10(10.6 \%)$ & $3(7.3 \%)$ & 0.753 & $4(11.4 \%)$ & $3(8.6 \%)$ & 1.000 \\
\hline Lateral component separation & $36(37.9 \%)$ & $16(39.0 \%)$ & 0.900 & $13(37.1 \%)$ & $15(42.9 \%)$ & 0.625 \\
\hline \multicolumn{7}{|l|}{ Mesh placement technique } \\
\hline Sublay (retro-rectus) & $58(63.7 \%)$ & $25(64.1 \%)$ & $0.026^{*}$ & $25(75.8 \%)$ & $20(60.6 \%)$ & 0.255 \\
\hline Onlay & $10(11.0 \%)$ & 0 & & $3(9.1 \%)$ & 0 & \\
\hline Bridge & $18(19.8 \%)$ & $7(17.9 \%)$ & & $5(15.2 \%)$ & $6(18.2 \%)$ & \\
\hline Underlay & $5(5.5 \%)$ & $7(17.9 \%)$ & & 0 & $7(21.2 \%)$ & \\
\hline Wound class II/III/IV & $46(48.4 \%)$ & $18(43.9 \%)$ & 0.628 & $18(51.4 \%)$ & $16(45.7 \%)$ & 0.632 \\
\hline Panniculectomy & $5(5.3 \%)$ & $1(2.4 \%)$ & 0.667 & $1(2.9 \%)$ & $1(2.9 \%)$ & 1.000 \\
\hline Excision of redundant skin & $14(14.7 \%)$ & $11(26.8 \%)$ & 0.094 & $3(8.6 \%)$ & $10(28.6 \%)$ & 0.062 \\
\hline Primary wound closure & $78(82.1 \%)$ & $34(82.9 \%)$ & 0.908 & $30(85.7 \%)$ & $30(85.7 \%)$ & 1.000 \\
\hline Mesh size $\left(\mathrm{cm}^{2}\right)$ & $449.8 \pm 257.5$ & $544.81 \pm 580.9$ & 0.241 & $457.55 \pm 268.7$ & $571.19 \pm 626.4$ & 0.377 \\
\hline Number of drains & $1.99 \pm 1.3$ & $2.21 \pm 1.1$ & 0.355 & $1.91 \pm 1.1$ & $2.24 \pm 1.1$ & 0.235 \\
\hline
\end{tabular}

*Significant at $p<0.05$

subacute rehabilitation centers $(16.1 \%$ vs. $11.8 \%$ nonelderly, $p=0.795)$.

The intraoperative complication rate $(2.9 \%$ in elderly with 0 in non-elderly, $p=1.000$ ), the need for wound VAC utilization $(22.9 \%$ in elderly vs. $14.3 \%$ in non-elderly, $p=0.356)$, wound infection rate $(8.6 \%$ in elderly vs. $5.7 \%$ in nonelderly, $p=1.000)$, wound necrosis rate $(2.9 \%$ in elderly vs. $0 \%$ in non-elderly, $p=0.493)$, hospital mortality rate $(2.9 \%$ in elderly vs. $2.9 \%$ in nonelderly, $p=1.000)$, the reoperation rate $(11.4 \%$ in elderly vs. $14.3 \%$ in non-elderly, $p=1.000)$ and the hospital length of stay (13.16 \pm 13.06 days in elderly vs. $11.58 \pm 11.53$ days in nonelderly, $p=0.606$ ) remained statistically similar.

\section{Discussion}

We have demonstrated that, when controlling for confounding variables with propensity score matching, abdominal wall reconstruction in the elderly population is not associated with greater complications than in nonelderly. There were no significant differences in operative 
Table 3 Comparison of post-operative outcomes of elderly vs non-elderly patients undergoing complex abdominal wall reconstruction with acellular porcine dermal matrix

\begin{tabular}{|c|c|c|c|c|c|c|c|}
\hline & \multicolumn{3}{|l|}{ Overall series } & \multicolumn{4}{|c|}{ Propensity-matched series } \\
\hline & Non-elderly, $N=95(\%)$ & Elderly, $N=41(\%)$ & $p$ value & Non-elderly, $N$ & $=35(\%)$ & $\begin{array}{l}\text { Elderly } N=35 \\
(\%)\end{array}$ & $\begin{array}{l}p \\
\text { value }\end{array}$ \\
\hline Intraoperative complications & $1(1.1 \%)$ & $2(4.9 \%)$ & 0.216 & 0 & & $1(2.9 \%)$ & 1.000 \\
\hline Need for wound VAC & $20(21.1 \%)$ & $9(22.0 \%)$ & 0.907 & $5(14.3 \%)$ & & $8(22.9 \%)$ & 0.356 \\
\hline Wound infection & $6(6.4 \%)$ & $3(7.3 \%)$ & 1.000 & $2(5.7 \%)$ & & $3(8.6 \%)$ & 1.000 \\
\hline Wound necrosis & $3(3.2 \%)$ & $1(2.5 \%)$ & 1.000 & 0 & & $1(2.9 \%)$ & 0.493 \\
\hline $\begin{array}{l}\text { Mechanical ventilation } \\
\text { required }\end{array}$ & $5(5.3 \%)$ & $9(22.0 \%)$ & $0.006^{*}$ & $2(5.7 \%)$ & & $6(17.1 \%)$ & 0.259 \\
\hline \multicolumn{8}{|l|}{ Discharge disposition } \\
\hline Home & $71(77.2 \%)$ & $21(56.8 \%)$ & $0.024 *$ & $26(76.5 \%)$ & $21(67.7 \%)$ & 0.795 & \\
\hline Skilled nursing facility & $4(4.3 \%)$ & $6(16.2 \%)$ & & $2(5.9 \%)$ & $4(12.9 \%)$ & & \\
\hline Subacute rehabilitation & $13(14.1 \%)$ & $7(18.9 \%)$ & & $4(11.8 \%)$ & $5(16.1 \%)$ & & \\
\hline Acute care hospital & $2(2.2 \%)$ & 0 & & $1(2.9 \%)$ & 0 & & \\
\hline $\begin{array}{l}\text { Discharged home with the } \\
\text { drain }\end{array}$ & $58(65.9 \%)$ & $22(62.9 \%)$ & 0.749 & $24(70.6 \%)$ & $18(60.0 \%)$ & 0.373 & \\
\hline Death & $1(1.1 \%)$ & $3(7.3 \%)$ & 0.083 & $1(2.9 \%)$ & $1(2.9 \%)$ & 1.000 & \\
\hline Reoperation & $22(23.2 \%)$ & $5(12.2 \%)$ & 0.141 & $5(14.3 \%)$ & $4(11.4 \%)$ & 1.000 & \\
\hline $\begin{array}{l}\text { Hospital Length of stay } \\
\text { (days) }\end{array}$ & $12.79 \pm 14.44$ & $17.49 \pm 26.84$ & 0.206 & $11.58 \pm 11.53$ & $13.16 \pm 13.06$ & 0.606 & \\
\hline
\end{tabular}

$V A C$ vacuum-assisted closure

*Significant at $p<0.05$

technique. Post-operative complications, ventilator utilization, and hospital and /ICU length of stay were similar. The type and frequency of discharge disposition were also similar for the two groups. These results are in concordance with those reported by Giordano et al. [24].

In our practice, we use biologic mesh for all patients who had an open abdomen management, multiple comorbidities and are high risk for infection (Hernia Working Group class 3, and 4) [25], complex re-operative surgery for recurrent hernia, patient on immunosuppressive medication or those who undergo CAWR in the acute setting. The main operative technique that we currently use is the posterior component separation with or without transversus abdominis release (TAR) and sublay (retro-rectus) mesh placement [20-22]. On occasions we may perform the anterior component separation. The use of synthetic mesh in complex cases and those associated with high risk for infection is associated with higher rates of complications such as infections, fistulas and need for explantation [10].

The elderly population has more chronic conditions, and thus it is expected that this may lead to a higher rate of postoperative morbidity and mortality [26]. One of the most feared complications after CAWR is wound infections [17]. Surgical site infection (SSI) is associated with a longer postoperative hospital stay, additional surgical procedures or stay in the intensive care unit and often higher mortality
[18]. In our study, the incidence of SSIs was comparable between the two groups and was associated with a statistically similar rate of reoperations before and after PSM. All the reoperations were for wound debridement only, and no mesh required explantation. The biological nature of the mesh offers this distinct advantage of mesh salvage in highrisk cases.

Post-operative mechanical ventilation (MV) is often required in the aging population and leads to higher rates of morbidity and increased healthcare costs $[27,28]$. In the current study, however, the need for MV was not significantly different from the non-elderly population. It has been reported that $45 \%$ of elderly patients require services such as home health care, skilled nursing facilities, and inpatient rehabilitation after elective surgery [29]. In our study, after adjusting for baseline characteristics with PSM, we did not find disposition in the elderly to be any different from the non-elderly.

Advanced age and comorbidities are often interrelated [30]. As expected in our study the comorbidities and frailty were more prevalent in the elderly but after PSM analysis this effect was found not to be significant. This may explain the lack of significant post-operative outcomes differences between our two age groups. The plausible explanation is that because of changing lifestyle and increased longevity the distribution of comorbidities is gradually becoming 
more uniformly distributed. This area remains to be explored further.

Importantly, old age, high burden of comorbidities and frailty have negative impact on decision making and proper access to surgery [31]. The strategy of 'prehabilitation' to increase functional capacity prior to a surgical procedure represents an ideal opportunity to identify modifiable risk factors, and introduce interventions to reduce the negative effect of comorbidity on the postoperative outcomes [32]. The key components of this multimodality strategy are medical optimization, preoperative physical exercise, nutritional support, and stress/anxiety reduction [33]. Several studies have shown that the favorable outcome can be achieved after employing prehabilitation in various types of surgeries. The CAWR specific prehabilitation, yet to be developed, may further improve the outcomes in this group of patients.

There are a number of strengths of this study. The main one is the use of propensity score matching allowing for controlling the confounders. The strict study design and the use of frailty as one of the co-dependent factors used to analyze outcomes after CAWR with biological mesh in the elderly are other strengths.

However, there are few study limitations as well, including the retrospective nature of our study and lack of data on recurrence rate and quality of life after CAWR. The number of patients in each group limits the statistical power to detect medium or small differences between groups. Furthermore, unlike randomized control trials, the introduction of unmeasured characteristics and confounders is one of the other potential limitations of PSM.

\section{Conclusions}

Outcomes after CAWR with a biological mesh did not differ between elderly and non-elderly patients and advanced age did not translate into poor outcome as compared to the non-elderly. Based on these findings, advanced age should not be regarded as an absolute or relative contraindication to CAWR.

\section{Compliance with ethical standards}

Conflict of interest The authors declare that they have no competing interests.

Ethical approval The study was approved by the Institutional Review Board.

Human and animal rights The study including human participants has been performed in accordance with the ethical standards of the Declaration of Helinski and its later amendments.
Informed consent Informed Consent was obtained from patients prior to all surgical procedures.

\section{References}

1. Ortman JM, Velkoff VA, Hogan H (2014) An aging nation: the older population in the United States. Hyattsville: US Census Bureau. https://www.census.gov/prod/2014pubs/p25-1140.pdf. Accessed 30 Apr 2019

2. Heller L, Chike-Obi C, Xue AS (2012) Abdominal wall reconstruction with mesh and components separation. Semin Plast Surg 26(1):29-35. https://doi.org/10.1055/s-0032-1302463

3. Latifi R, Leppäniemi A (2012) Complex abdominal wall defects and enterocutaneous fistulae in the era of biological mesh: did we make any real progress? World J Surg 36:495-496

4. Peralta R, Latifi R (2012) Long-term outcomes of abdominal wall reconstruction. What are the real numbers? World J Surg. 36:534-538

5. Turrentine FE, Wang H, Simpson VB, Jones RS (2006) Surgical risk factors, morbidity, and mortality in elderly patients. J Am Coll Surg 203(6):865-87717116555

6. WHO (2019) Definition of an older or elderly person. Who.int. https://www.who.int/healthinfo/survey/ageingdefnolder/en/. Accessed 02 Feb 2019

7. Mather M (2016) Fact sheet: aging in the United States. Population Reference Bureau. https://www.prb.org/aging-unitedstatesfact-sheet/. Accessed 02 Feb 2019

8. Primus FE, Harris HW (2013) A critical review of biologic mesh use in ventral hernia repairs under contaminated conditions. Hernia 17(1):21-30. https://doi.org/10.1007/s10029-012-1037-8

9. Slater NJ, van der Kolk M, Hendriks T, van Goor H, Bleichrodt RP (2013) Biologic grafts for ventral hernia repair: a systematic review. Am J Surg 205:220-230

10. Diaz JJJ, Cullinane DC, Khwaja KA et al (2013) Eastern Association for the Surgery of Trauma: management of the open abdomen, part III-review of abdominal wall reconstruction. J Trauma Acute Care Surg 75:376-386. https://doi.org/10.1097/TA.0b013 e318294bee 3

11. Latifi R, Samson D, Haider A et al (2017) Risk-adjusted adverse outcomes in complex abdominal wall hernia repair with biologic mesh: a case series of 140 patients. Int J Surg 43:26-32

12. Muysoms FE, Miserez M, Berrevoet F et al (2009) Classification of primary and incisional abdominal wall hernias. Hernia 13(4):407-414

13. Horan TC, Andrus M, Dudeck MA (2008) CDC/NHSN surveillance definition of healthcare associated infection and criteria for specific types of infections in the acute care setting. Am J Infect Control 36:309-332

14. Collaborative GlobalSurg (2018) Surgical site infection after gastrointestinal surgery in highincome, middle-income, and lowincome countries: a prospective, international, multicentre cohort study. Lancet Infect Dis 18:516-525

15. Morales-Conde S, Suárez-Artacho G, Socas M, Barranco A (2013) Influence of fibrin sealant in preventing postoperative seroma and normalizing the abdominal wall after laparoscopic repair of ventral hernia. Surg Endosc 27:3214-3329. https://doi. org/10.1007/s00464-013-2894-7

16. Velanovich V, Antoine H, Swartz A et al (2013) Accumulating deficits model of frailty and postoperative mortality and morbidity: its application to a national database. J Surg Res 183:104-110

17. Muysoms F, Campanelli G, Champault GG et al (2012) EuraHS: the development of an international online platform for 
registration and outcome measurement of ventral abdominal wall hernia repair. Hernia 16:239-250

18. Latifi R (2016) Practical approaches to the definitive reconstruction of complex abdominal wall defects. World J Surg 40:836-848

19. Latifi R (ed) (2017) Surgery of complex abdominal wall defectsa practical approach, 2nd edn. Springer, New York. https://doi. org/10.1007/978-3-319-55868-4

20. Albanese AR (1951) Gigantic median xipho-umbilical eventration; the method for treatment. Rev Asoc Med Argent 65(709-710):376-378

21. Novitsky YW, Elliott HL, Orenstein SB et al (2012) Transversus abdominis muscle release: a novel approach to posterior component separation during complex abdominal wall reconstruction. Am J Surg 204:709-716

22. Gibreel W, Sarr MG, Rosen M, Novitsky Y (2016) Technical considerations in performing posterior component separation with transverse abdominis muscle release. Hernia 20(3):449-459. https ://doi.org/10.1007/s10029-016-1473-y

23. von Elm E, Altman DG, Egger M et al (2007) STROBE initiative. strengthening the reporting of observational studies in epidemiology (STROBE) statement: guidelines for reporting observational studies. BMJ 335:806-808

24. Giordano S, Schaverien M, Garvey PB et al (2017) Advanced age does not affect abdominal wall reconstruction outcomes using the acellular dermal matrix: a comparative study using propensity score analysis. Am J Surg 213:1046-1052

25. Breuing K, Butler CE, Ferzoco $S$ et al (2010) Incisional ventral hernias: review of the literature and recommendations regarding the grading and technique of repair. Surgery 148:544-558
26. Kim SW, Han HS, Jung HW, Kim KI, Hwang DW, Kang SB et al (2014) Multidimensional frailty score for the prediction of postoperative mortality risk. JAMA Surg 149(7):633-640

27. Needham DM, Bronskill SE, Calinawan JR et al (2005) Projected incidence of mechanical ventilation in Ontario to 2026: preparing for the aging baby boomers. Crit Care Med 33:574-579

28. Carson SS, Cox CE, Holmes GM, Howard A, Carey TS (2006) The changing epidemiology of mechanical ventilation: a population-based study. J Intensive Care Med 21:173-182

29. Sacks GD, Lawson EH, Dawes AJ et al (2015) Which patients require more care after hospital discharge? An analysis of postacute care use among elderly patients undergoing elective surgery. J Am Coll Surg 220(6):1113-1121

30. Meghani SH, Buck HG, Dickson VV et al (2013) The conceptualization and measurement of comorbidity: a review of the interprofessional discourse. Nurs Res Pract 2013:192782. https://doi. org/10.1155/2013/192782

31. Carli F, Zavorsky GS (2005) Optimizing functional exercise capacity in the elderly surgical population. Curr Opin Clin Nutr Metabolic Care 8(1):23e32

32. Wynter-Blyth V, Moorthy K (2017) Prehabilitation: preparing patients for surgery. BMJ. https://doi.org/10.1136/bmj.j3702

33. Banugo P, Amoako D (2017) Prehabilitation. BJA Educ. 17(12):401e5

Publisher's Note Springer Nature remains neutral with regard to jurisdictional claims in published maps and institutional affiliations.

\section{Affiliations}

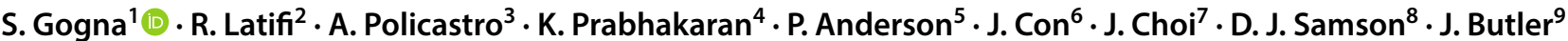

S. Gogna

Shekhar.gogna@wmchealth.org

A. Policastro

Anthony.policastro@wmchealth.org

K. Prabhakaran

Kartik.prabhakaran@wmchealth.org

P. Anderson

Patrice.anderson@wmchealth.org

J. Con

Jorge.con@wmchealth.org

J. Choi

James.choi@wmchealth.org

D. J. Samson

david.samson@wmchealth.org

J. Butler

jonathan.butler@wmchealth.org

1 Department of Surgery, Westchester Medical Center, New York Medical College, 100 Woods Road, Taylor Pavilion, E-348, Valhalla, NY 10595, USA

2 Westchester Medical Center, School of Medicine, New York Medical College, Valhalla, NY 10595, USA

3 Medical Director SICU, PCU, Trauma and Critical Care, Department of Surgery, Westchester Medical center, School of Medicine, New York Medical College, 100 Woods Road, Taylor Pavilion, Office E-136, Valhalla, NY 10595, USA

4 Division of Trauma, Acute Care Surgery and Burns, Department of Surgery, Westchester Medical center, School of Medicine, New York Medical College, 100 Woods Road, Taylor Pavilion, Office E-150, Valhalla, NY 10595, USA

5 Trauma Intensive Care Unit, Department of Surgery, Westchester Medical center, School of Medicine, New York Medical College, 100 Woods Road, Taylor Pavilion, Office E-145, Valhalla, NY 10595, USA

6 Department of Surgery, Westchester Medical center, School of Medicine, New York Medical College, 100 Woods Road, Taylor Pavilion, E-131, Office \#E145, Valhalla, NY 10595, USA

7 Department of Surgery, Westchester Medical Center, New York Medical College, 100 Woods Road, Taylor Pavilion, E-348, Valhalla, NY 10595, USA

8 Department of Surgery, Clinical Research Unit, Westchester Medical Center, 100 Woods Road, Taylor Pavilion, Office E-348, Valhalla, NY 10595, USA

9 Clinical Research Unit, Westchester Medical Center, 100 Woods Road, Taylor Pavilion, Office E-348, Valhalla, NY 10595, USA 